\title{
A espessura do encontro
}

\author{
Luis Eduardo Ponciano Aragon ${ }^{1}$
}

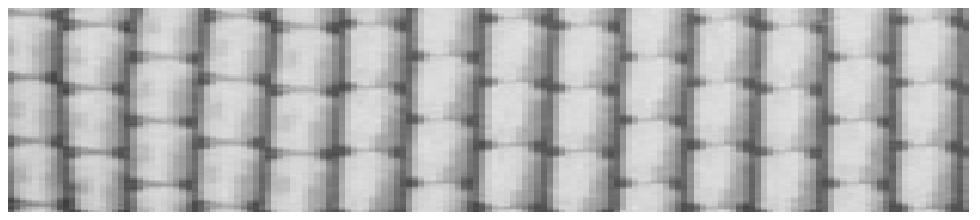

ARAGON, L. E. P. The denseness of interface, Interface - Comunic, Saúde, Educ, v.7, n.12, p.11-22, 2003.

Relying on the cartographic method, this article proposes an analysis of the contemporary element of Medicine, by means of its interface with psychoanalysis. The cartographic method was chosen to avoid both the perspective of dialectical analysis and the isolation of the "observer" relative to the observed object. The medical scene, being technological, is open to levels of communication/contamination that exceed the usual doctor/patient relation, so that it may support the complexity of interfaces, including unconscious and virtual elements. This complexity, when taken into account, implies in a particular ethic. What is proposed is the use of a so-called "near-concept" to aid in the cartographic task of determining the levels that interfacing comprises. There is a rejection of the voluntarism that leads to the production of "conduct manuals", in order to seek "energy lines" that cross contemporary space and the duo immersed in it, such lines being regarded as pre-individual.

KEY WORDS: Medicine; Psychoanalysis; Cartography; ultrasonography.

Utilizando o método cartográfico, este trabalho propõe uma análise do contemporâneo da Medicina, por meio de seu encontro com a Psicanálise. A escolha do método cartográfico tem o intuito de evitar tanto uma perspectiva de análise dialética, quanto o isolamento do "observador" de seu objeto. A cena médica, tecnológica, abre-se para receber planos de comunicação/contaminação que ultrapassam a habitual relação médico-paciente. Isto para sustentar a complexidade dos encontros, comportando fatores inconscientes e virtuais. Complexidade esta que, levada em consideração, implica uma ética particular. Propõe-se o uso do que foi chamado "quase-conceito" para auxiliar na tarefa cartográfica de determinar planos compostos no encontro. Rejeita-se o voluntarismo que acarreta a produção de "manuais de conduta", para buscar "linhas de força" que atravessam o espaço contemporâneo e os nele imersos, linhas estas consideradas como pré-individuais.

PALAVRAS-CHAVE: Medicina; Psicanálise; Cartografia; ultrassonografia.

${ }^{1}$ Médico cardiologista, psicanalista, membro do Departamento Formação em Psicanálise do Instituto Sedes Sapientiae, São Paulo. <aragonn@uol.com.br> 
Moça negra, alta, bonita. Logo às primeiras palavras percebe-se que é uma pessoa inteligente e alegre. Não esconde, no entanto, a apreensão natural de quem se encontra em um hospital para fazer exames. Neste caso, exame de seu bebê $\hat{e}^{2}$, ainda em gestação.

O local era destinado a pesquisar problemas cardíacos fetais. Assim, comportava equipamentos de alta tecnologia e profissionais especializados. Estamos no setor de ecocardiografia.

A imaginação do leitor talvez o conduza a um ambiente sofisticado, tranqüilo, confortável, e quem sabe, até mesmo acolhedor. Se assim foi concebida a cena, o foi apenas com o auxílio de uma benfazeja e protetora traição do desejo que manipula os sentidos.

Estamos, a paciente e eu, em um hospital universitário. Ali, em pequenos espaços, com poucos requintes estéticos, algumas minguadas plantas tentam quebrar a atmosfera densa $e$ fria.

Em um hospital universitário vive-se uma vida muito singular, que transborda trabalho. Pacientes surgem aos borbotões vindos de todas as partes do país, e mesmo de outros países (Amaral, 1999)3. Sotaques diversos tentam dar contorno a queixas por vezes incompreensíveis, por se apresentarem em uma língua extremamente regional. A demanda pelo saber médico, além de chegar em quantidade elevada, carrega também uma intensidade extrema.

O tempo falta para refeição, para o estudo, para o lazer. E os pacientes gritam, não só com palavras, mas com todo o seu ser pela certeza de um diagnóstico, um tratamento e a cura daquilo que os consome em sofrimento. Parece óbvio, mas as pessoas só vão ao hospital porque estão sofrendo e, com esta atitude, deixam implícito que será ali que o alívio se apresentará. Mesmo que este anseio visceral não esteja a todo momento na mente da equipe de atendimento, a tensão se revela em cada olhar, cada gesto, cada solicitação, por menor que seja.

É nesta micro-comunidade de alta complexidade relacional que se dá o encontro.

$\mathrm{Em}$ instantes põe-se a funcionar o maquinismo tecnológico - que em apenas um de seus aspectos tenta dar conta da tensão revelada acima. A moça deitada, barriga para cima, expondo para um desconhecido a parte do seu corpo que encerra o seu maior mistério. Mistério da criação, do ser si própria e ser outra, de ser entranha e ex(es)tranho.

Sentado a seu lado, eu sou o pólo da dupla (ou do trio) destinado a manejar o instrumento do progresso da Medicina. Meus olhos treinados não se opõem à captura das imagens que trazem as profundezas do corpo à superfície. Não se pode dizer que esta penetração consentida seja fruto de uma relação de amor. $O$ interesse de ambos é colhido pela curiosidade científica que não se detém em intimidades, e põe a descoberto o que antes era privado. Quando a atenção da paciente desvia-se da tela para mim, é na intenção desesperada de interpretar na minha fisionomia algo que pudesse ser bom ou ruim. As palavras nervosas, claramente buscam dissimular - sem conseguir - a preocupação acerca do que o meu conhecimento poderia depreender daquele estranho jogo de luz e sombra.
2 Utilizo a palavra mais popular, bebê, no lugar da que seria cientificamente mais apropriada, a saber: feto. Faço esta opção para enfatizar o aspecto psicológico complexo que se apresenta como mãebebê-em-processo de gestação, e para me afastar da concepção mais científica do ser A palavra feto será utilizada quando o contexto for

predominantemente científico.

${ }^{3}$ Acompanhando a vida dos médicos residentes em um Hospital Universitário a autora revela de forma clara e viva o difícil cotidiano vivido neste ambiente.

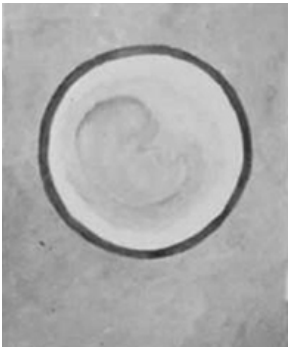


${ }^{4}$ Não só de guerra, mas também de tragédia. $\mathrm{O}$ desenvolvimento do ecobatímetro ocorreu fundamentalmente para evitar um outro acidente como o do transatlântico Titanic.

\section{A angústia}

É interessante lembrar que o ultra-som aplicado à Medicina foi uma técnica que surgiu a partir da situação de guerra ${ }^{4}$. Os tripulantes dos submarinos necessitavam "ver" os relevos do fundo do mar e os possíveis obstáculos ao seu progresso. Mais ainda, era preciso ante-ver. Antecipar a possibilidade de colisões e também a identificação de possíveis inimigos para serem atacados.

A similitude das duas situações, tão distanciadas no tempo, não deve ser considerada mero acaso. Em ambas, a angústia apreensiva domina o ambiente escuro. A vontade de saber tornou-se necessidade. Antecipar o acontecimento sinistro atacando o objeto ameaçador. Em nossa história, o acontecimento só se realiza totalmente com o nascimento, e o objeto a ser atacado com a propedêutica médica é o bebê doente.

$\mathrm{O}$ costume me faz escorregar em armadilhas do pensamento. $\mathrm{O}$ bebê em questão é potencialmente doente. A gestante nada sente, o bebê se movimenta e é parte ativa na comunicação com ela. Ambos já constróem uma história de sensações, fabulações e afetos.

Percebe-se que, nesta situação, a maquinaria médica, com seus instrumentos e ideais, se descola da necessidade de intervir sobre um sofrimento - ou de forma mais geral um mal - atual, para dedicar-se a buscar um. Este leve deslocamento terá enormes conseqüências na vida das pessoas atendidas. Isso porque, em um grande número de casos, a identificação de um problema com o feto não reverte na possibilidade de intervenção. Há ainda os casos em que o diagnóstico é feito incorretamente. Nestas situações cria-se um sério problema para a família, com conseqüências imprevistas na estrutura psicológica desta.

Por esta ótica, o médico armado de seu instrumental é um intruso que, abrupto, invade a relação familiar que se formou com a gravidez. Muitas vezes o profissional não se dá conta da dimensão da capacidade de intrusão que a sociedade científica colocou em suas mãos, e nem ao menos usa da cerimônia - tão comum em povos do oriente - ao entrar em um novo "lar".

Não se costuma lembrar que o ultra-som surgiu em meio à ansiedade por ver algo que normalmente não pode ser visto, não com nossos próprios olhos. E assim se nega a angústia que alaga a escura sala de exames.

Esta face da Medicina faz-nos lembrar o grande número de histórias envolvendo a desenfreada curiosidade humana. Só para citar dois dos exemplos mais conhecidos, podemos lembrar o do Gênesis e do Édipo Rei. Em ambos a curiosidade arrogante do homem, mesmo após as advertências, o conduz para a dor. Não quero trazer para a discussão uma visão moralista ou religiosa. Também não desconheço os benefícios que a tecnologia médica traz - em várias situações - uma vez estabelecida. É fundamental, entretanto, radicalizar o pensamento, para poder pensar sobre situações cotidianas que a, rigor, não são objeto de reflexão. E entre elas a própria condução do progresso tecnológico. Este progresso considerado como inescapável $e$ inquestionável quanto à sua produção e mesmo seus fins. A que serve a vontade de saber sobre o interior do corpo? A ânsia de antecipar o futuro? No caso da avaliação do feto não se trata de uma atitude preventiva, como uma vacina ou como medidas de saneamento básico. Isso, pois, não visa proteger contra males específicos e conhecidos. Trata-se aqui 
de querer saber.

Não podemos nos contentar com respostas ingênuas ao movimento de conhecer a qualquer preço (ou, o que é quase a mesma coisa, sem pensar no preço). Querer ajudar é uma fala humanista, romântica, que não comporta toda uma série de aspectos que determinam o desenvolvimento tecnológico utilizado na Medicina. Podemos, aqui, apenas sugerir alguns caminhos de aprofundamento em direção às motivações em jogo.

Apesar de ser de domínio público o interesse econômico que envolve a produção de tecnologia, os profissionais médicos não costumam discutir o impacto desta questão em suas atividades quando reunidos em congressos ou simpósios. Nem mesmo durante a prática diária. Os poucos que o fazem não comunicam ou não têm espaço para comunicar suas dúvidas $e$ apreensões. O próprio patrocínio dos encontros científicos é feito pelas empresas interessadas em vender tecnologia.

Toda forma de acúmulo de saber carrega consigo um jogo de poder. Quem detém o conhecimento se distancia hierarquicamente de quem não o possui. Isto dificulta perceber que o paciente tem o direito, e deveria poder exercê-lo, de se recusar a ser submetido a uma determinada abordagem. No entanto, este paciente é reduzido a uma posição de não saber, que, no limite, arranca a autoridade que tem sobre o que é feito consigo. $O$ jargão profissional tem a função de estabelecer a diferença de valor entre indivíduos em um determinado campo, mais do que esclarecer melhor algum fenômeno ${ }^{5}$.

Além dos interesses econômicos e do jogo de poder, há uma questão compartilhada por médicos e pacientes que é o medo da perda de controle, sobre a vida e sobre a integridade física. Conhecer, saber antecipadamente sobre algo oculto, traz a sensação - muitas vezes ilusória - de ter sob controle os eventos incontroláveis da vida.

\section{A rapidez}

Retornando a nossa sala de exames, a paciente me conta que está ali porque foi descoberto algum problema com seu bebê. Não sabe dizer qual é o problema identificado pela ultra-sonografia obstétrica de rotina. Vejo, pelo encaminhamento da equipe de Medicina fetal, que o diagnóstico é de uma alteração genética incompatível com a vida pós-natal. O diagnóstico que eu poderia realizar seria mais um fator para a certeza do julgamento prévio. Realmente o feto apresentava a cardiopatia esperada, mas e quanto ao bebê esperado por aquela mãe? Em todo o acompanhamento médico desta gestante pouco foi o tempo dispensado para que se entrasse em contato com este bebê. Não se trata de um caso isolado. O cuidado com a capacidade diagnóstica suplanta em muito o cuidado com a vida afetiva da gestante, seu bebê e o restante da família. Existem, é claro, exceções. Como também existem situações de crueldade inimaginável.

Médicos são, em sua maioria, pessoas cordiais e bem intencionadas. Mas estas qualidades não os poupam de entrar no alinhavo social do nosso tempo. Os pacientes também não. Sofrem o impacto, por exemplo, da necessidade de rapidez (Virilio, 1996). Rapidez que engole distâncias e cria uma nova percepção de mundo. Rapidez que - com perdão da pobre rima -

\author{
${ }^{5}$ Um exemplo cotidiano \\ é o diagnóstico de \\ "bloqueio do ramo \\ esquerdo". Quando \\ pergunto aos pacientes \\ que receberam este \\ diagnóstico o que \\ entendem por esta \\ expressão, a quase \\ totalidade diz acreditar \\ ter uma obstrução \\ coronariana "no lado \\ esquerdo do coração". \\ Na verdade este \\ "conjunto de palavras" \\ refere-se a um caminho \\ percorrido pelo \\ impulso elétrico que \\ varre o coração. \\ Quando o trajeto varia \\ com relação ao padrão \\ de normalidade diz-se \\ que há um bloqueio. $\mathrm{O}$ \\ mesmo pode ser \\ normal para a pessoa \\ não denotar qualquer \\ patologia.
}

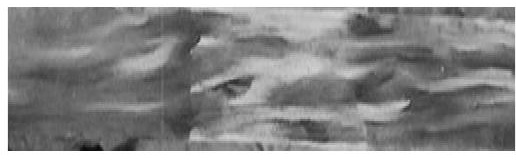


está fadada a tornar-se rispidez nos encontros.

Além da rapidez que sacia a curiosidade do que só se revelaria ao nascimento, existem outras. A rapidez que permite com que anos de estudo $e$ aprimoramento tecnológico se apresentem na instantaneidade de um diagnóstico. A rapidez que impele para não ficar, não se deter, não "perder tempo" - muitas vezes, mas não só - por que "tempo é dinheiro" e todos querem/têm que sobreviver em uma sociedade que exclui quem não pode consumir. A rapidez que parece vencer o medo da doença e da morte.

Todas essas perspectivas da necessidade de rapidez, e outras mais, moldam um tipo de homem que está sempre em trânsito. Não está aqui, nem ali, mas de passagem. $\mathrm{O}$ espaço habitado por este homem contemporâneo é caracterizado por paisagens que mudam com freqüência (Sant'Anna, 2001), trazendo consigo uma sensação de desenraizamento. Dos lugares, das pessoas, $e$ talvez até de si mesmo. Chega mesmo a haver um envelhecimento do presente antes mesmo dele se apresentar. Um turista em viagem à Itália pode não se surpreender tanto com a inclinação da torre de Piza, pois por seus olhos já passaram inúmeras perspectivas da mesma pela televisão, por revistas, pela internet. Da mesma forma, o feto anormal pode ser apenas mais um na vasta seqüência coligida por um ecocardiografista.

Não é necessário esforço para perceber o ataque a tudo que poderia singularizar a relação médico-paciente.

Não se trata de proceder a uma caça às bruxas. Muito menos de realizar um manual de condutas. Abdicamos da busca por culpados, para tentar uma aproximação da situação que permita identificar forças em jogo. A necessidade de velocidade é apenas uma das peças jogadas no tabuleiro.

\section{O cientificismo}

Médico e paciente também sofrem o peso da hegemonia do pensamento contemporâneo científico positivista. Este promove uma série de recortes $e$ valorações que freqüentemente ficam apagadas por um automatismo de pensamento que torna difícil questionar sua pertinência.

No referencial científico habitual há uma valoração da estatística em detrimento do singular. Há também a tendência de considerar o corpo como uma máquina e a patologia como um mau funcionamento, no lugar de um corpo complexo, emocional, em constante mudança, e a patologia como forma de comunicação, ou ao menos, sofrimento com representação psíquica particular. Neste campo preconiza-se comumente a independência do observador quanto ao observado, apagando a intensa relação afetiva que qualquer médico ou paciente tem consciência ou intui.

Placebo e sugestão, são pontos periféricos, quando não rejeitados, da teoria médica dita científica, o que leva muitos profissionais a abrirem mão de um extenso campo de intervenção, eficaz e pouco custoso. A assepsia do conhecimento objetivo pretende alienar e tornar obsoleta a densidade da figura do médico, constituída ao longo de milhares de anos. Na objetivação do corpo o doente, assim como o médico, vai se desenraizando de sua história. Para além do processo identificatório e imaginário que está em jogo no processo de influência do médico quanto ao paciente existe, também, a escuta. Esta última, objeto privilegiado deste trabalho, busca sustentar a complexidade da relação 
que transforma médico e paciente, aquém da divisão sujeito/objeto.

Com certa facilidade as pessoas de determinada época acreditam que a verdade está encerrada na pesquisa científica contemporânea. Não é fácil conceber que toda ciência trabalha com modelos transitórios, sempre influenciados pela necessidade de ordem da comunidade, o que, muitas vezes, se transforma em dogmatismo, como a idéia de que a terra era o centro do sistema solar (Alves, 1996). Considero importante o esforço de sustentar uma postura inquiridora, para que a ética que permeia cada bloco de atitudes possa ser percebida.

O método: como trazer para o visível o invisível? Realçando até este ponto, entre tantos outros fatores possíveis, apenas o impacto da rapidez e do cientificismo no campo de relação médico- paciente, creio já termos meios para avançar no terreno problemático (no sentido de gerar questões) deste encontro.

Vivemos em uma época na qual a velocidade e a ciência não são, com frequência, questionadas. Muito do que encarnam as atitudes não é ou não pode ser pensado. Assim o paciente se deixa engolir, sem reservas, a uma curiosidade apressada... e o médico também.

Mas como dar visibilidade a fatores que estão na raiz da determinação de nossos atos? Como passar a enxergar coisas que sempre estiveram aí (como poderiam não estar) e que, por hábito, fugiram da nossa observação, mas nem por isso deixaram de conduzir nossos passos?

O método cartográfico, aqui utilizado, possibilita algumas respostas.

A cartografia, ao detectar paisagens, aclives e declives, cria formas de expressão, e vai se formando junto com o território (Rolnik, 1987). Vai dando lugar ao que está em processo de constituição, não excluindo o cartógrafo do processo. Não se trata de trabalhar com mapas. Estes usam escalas baseadas em diferenças do relevo, do clima, da vegetação. Estas diferenças são determinadas por códigos previamente determinados. Na Medicina podemos conceber os critérios de normalidade como mapas, ou seja, um metro-padrão para medir e classificar aquilo que se observa. Se o profissional se atém à necessidade de aplicar o mapa à experiência (ou ao território), tudo que diferir daquele tenderá a ser rejeitado.

O cartógrafo, ao contrário, busca produzir uma língua, uma existência, no processo de mistura e separação das situações que percorre. Tenta dar voz àquilo que surge constantemente na atualidade de seu tempo, procurando não excluir o que é estranho ou angustiante por não ser previamente mapeado.

Tendo em mente esta perspectiva ética, vamos prosseguir com o acompanhamento das situações de encontro.

Concretamente uma atitude que me permitiu por em marcha a atitude de abrir espaço para compartilhar da experiência foi a de aumentar o número de encontros.

Realizei durante dois anos os exames de ecocardiografia fetal no Hospital São Paulo, o que resultou em minha dissertação de mestrado sobre este tipo de investigação (Aragon, 1996). Propus às gestantes que tinham bebês nos quais se suspeitava de alguma anormalidade cardíaca, que retornassem a cada quinze dias para a realização de novo exame. Não havia expectativa de mudança significativa no diagnóstico fetal, mas uma proposta de passar mais tempo com 


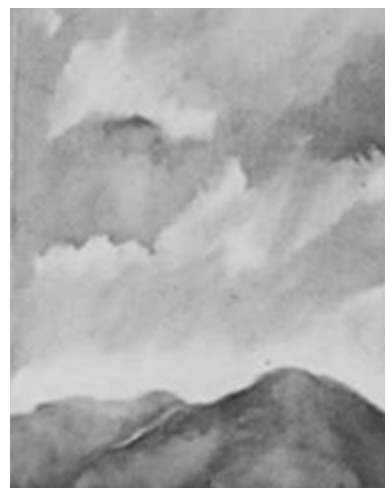

estas gestantes e seus familiares. Acredito ter sido esta a demanda quando do primeiro encontro, $e$ assim essas famílias puderam me ajudar a aprender $o$ caminho para minimizar o seu sofrimento. Passo a trilhar novamente este percurso, agora acompanhado do leitor.

\section{A espessura do acontecimento}

As perguntas feitas pelas pacientes são muitas vezes diretas, como: "está vendo algum problema com o bebê, doutor?". Outras tantas não expõem a preocupação assim, de chofre, como: “o que dá para ver nesse exame?”. Nestas situações, o medo se mostra sem rodeios, muitas vezes colorido com fantasias que procuram dar uma forma ao que se espera de pior. Estas fantasias dificilmente correspondem ao que pode ser encontrado no bebê pelo exame. No entanto, a estratégia do fantasiar, além de revelar, também limita os medos. Medos "sem nome" pela própria característica da situação, a de querer saber sobre o interior do corpo. Saber mediado e não imediato, o que abre um amplo espaço para o fantasiar.

Existem exclamações que comunicam os movimentos do bebê, algumas vezes interpretações do significado destes. Há também perguntas em que o médico vai intermediar a interpretação como "quando mexe aqui é o pé ou a mão?". Fica evidente então a força vital do bebê em gestação. Por meio de seus movimentos e das falas da gestante, ganha relevo subjetivo o ser em formação. Com isso, trava-se uma luta para sustentar a presença do bebê sadio na cena ecocardiográfica.

Sob uma determinada perspectiva, as questões e comunicações colocadas no momento do encontro, asseguram o papel social dos personagens. Médico $e$ paciente. Apesar disto, há ao mesmo tempo um atravessamento de signos que tem limites mais imprecisos, e que mergulha o encontro em uma outra área de sentido. Este atravessamento supera a capacidade verbal de comunicação por sua complexidade e/ou pela impropriedade das palavras em fazê-lo. É um campo predominantemente regido pelo afeto.

Muitos são os afetos disparados nesta situação. Nem todos serão apreendidos conscientemente na hora. Quem sabe só a posteriori, se o forem, uma boa parte dos afetos poderão ser nomeados.

Medo da morte, da sua própria e do bebê; medo de lidar com a impotência de não ter controle sobre o que ocorre no corpo; necessidade de sustentar um ideal de filho e de relação; sensação de invasão do seu interior; sensação que envolve interpretar a gravidez por uma perspectiva científica, analítica e muitas vezes mecanicista; afeto de curiosidade; expectativa quanto à capacidade de ser mãe e gerar uma criança saudável; medo de que suas atitudes possam ter ocasionado algum mal ao bebê; e talvez até o temor inconsciente de ver revelado um repúdio à concepção. A lista de possibilidades é virtualmente infinita em extensão e composição.

O que interessa destacar aqui pode ser didaticamente dividido em dois pontos. O primeiro é perceber que existe uma multiplicidade de encontros convergindo no mesmo acontecimento. Fator que não pode ser reduzido à idéia de que a paciente está ali apenas para saber se há ou não um problema com o feto, e o médico para realizar este diagnóstico. O segundo diz respeito ao compartilhar dos afetos que se apresentam no encontro, rompendo a ilusória distância entre médico e paciente. 


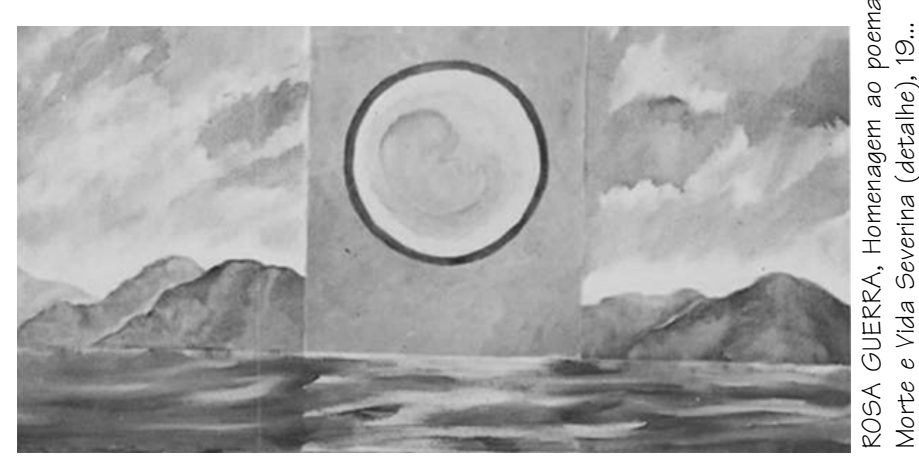

\section{A delicadeza}

Percebemos que as falas e os gestos que habitam a sala de exames, como em toda relação, fazem parte de uma complexa comunicação. Uma boa parte dos medos, fantasias e expectativas que estão presentes não são conscientes, nem para o paciente, nem para o médico. Isso não quer dizer que não existam.

Estas descobertas não ocorreram de uma hora para outra. Também não foram encontradas prontas em um livro. Decorreram de aspectos presentes, mas quase virtuais, que permearam os encontros. Fatores como delicadeza $e$ sutileza são pouco comentados no meio médico, mas são de grande importância quando se trata de tentar aprender com o outro a melhor maneira de se aproximar e se relacionar.

Resgato estes "quase-conceitos", delicadeza e sutileza, para que nos ajudem na tarefa cartográfica. Escolho propositalmente qualidades de ações, formas de atitude, que dificilmente se prestam a uma determinação objetiva. Com isso temos maior liberdade para refletir sobre a experiência.

Ser delicado com o outro implica não chegar de sopetão com uma verdade já pronta. Implica uma certa lentidão no trato com o tempo, para que seja possível observar, interagir e encontrar a medida certa. Só assim é possível perceber que encaminhamento dar à angústia, sem negá-la, ou se render a ela. Assim, aprendi que todas as gestantes, quando impactadas por uma notícia ruim, tentavam conceber uma figura de seu bebê. Notei que, na maior parte das vezes, exprimem nessas figuras a expectativa de uma monstruosidade. $\mathrm{O}$ que não se vê e é considerado como negativo é normalmente palco das mais terríveis cenas da imaginação.

Como enfrentar a gravidade de uma notícia ruim, no sentido de minimizar ao máximo a dor, que é o principal objetivo do médico?

É necessário cultivar a possibilidade de ficar com a experiência sem querer bani-la prontamente. Só isto já pode evitar condutas catastróficas, mas infelizmente comuns, como é o caso de dizer para a família que o feto tem um grave problema, talvez não sobreviva aos nove meses de gestação, e que voltem para controle da patologia no mês seguinte.

Conceder um mínimo de tempo que permita se colocar na posição de quem recebe a notícia, e terá que conviver com ela. Este tempo pode trazer consigo a sutileza que emerge da possibilidade de não se sentir diferente, fora do problema, $e$ ter a humildade de entender que foi a vontade do nosso saber que tornou possível esta triste situação.

O meu exercício de sutileza foi procurar em cada caso dar as informações de que dispunha, na medida da demanda da família. Com as palavras mais simples que conseguia dizer. Para minha surpresa, a capacidade de compreensão das gestantes é muito grande. E ao contrário do que se poderia imaginar, quanto 
mais informadas e seguras do que está ocorrendo na mente do examinador, mais tranqüilas e cooperativas se mostram, mesmo que o médico espere ou diagnostique coisas muito ruins.

Passei, então, a dedicar o tempo necessário para tirar as dúvidas da gestante sobre as descobertas que o saber médico produziu. Em todos os casos, fazia desenhos do coração, explicando a diferença do que é considerado normal e o que foi encontrado no seu bebê. A maioria das gestantes pedia para levar os desenhos, para assim explicar o problema para os familiares e vizinhos. Vale dizer que além das fantasias da gestante, os familiares e conhecidos colaboram freqüentemente para a piora da situação, aumentando ao infinito a angústia já muito grande.

Poder esperar as perguntas chegarem, falar do seu conhecer aos poucos, na medida que há um espaço para fazê-lo, usar palavras compreensíveis, têm resultados incríveis. É a postura que alinho com o que chamo de sutileza. São atitudes que não chamam muito a atenção, ao contrário, passam quase desapercebidas, mas talvez por isso mesmo consigam penetrar e produzir mudança. Não se trata, de forma alguma, de ser "bonzinho" ou de tentar sentir a mesma coisa que a gestante. Também não estou falando de uma cordialidade automática, um simples obedecer a regras socialmente impostas. A atitude delicada e sutil preserva a diferença entre as pessoas, a autenticidade de cada uma no encontro com a situação, o que não impede que haja uma porosidade de afetação. Um deixar-se penetrar pela emoção que circula naquele momento único.

Assim, o aprendizado não cessa, e o campo de ação médica amplia-se muito. É comum, por exemplo, que o casal se sinta responsável pela tragédia desvelada. Um tombo, um medicamento, a história de patologias de família, a qualidade ruim de si próprios como genitores, ou mesmo a rejeição da gravidez que surgiu em um momento imprevisto ("um descuido"), são alguns dos modos de culpabilização do casal. Poder desfazer estes roteiros é, no meu entender, uma das atitudes mais nobres do médico nesta situação. Digo isto porque ao ouvir o casal quando retorna, vê-se que a forma como o encontro se deu no consultório ou na sala de exames repercute intensamente "nos bastidores”. Depressão, crise conjugal, rejeição pela família, são só alguns dos problemas que podem ser minimizados. Se o médico não está aberto para "sentir com", pode ignorar estas questões, considerando-as como fora de sua alçada.

Falo de situações cotidianas e atitudes simples, adquiridas a partir da abertura para o aprender com a experiência. Não nego, no entanto, que minha formação psicanalítica ajudou na elaboração dessas experiências.

\section{Medicina e Psicanálise se encontram}

O fato de ser psicanalista me deu uma oportunidade que, ao ser compartilhada, pode reverter em benefício da Medicina.

A moça do caso aqui analisado, como era esperado, perdeu seu bebê. Eu acompanhei toda a gravidez e estava lá no momento do parto. Uma menina, portadora de uma síndrome genética incompatível com a vida, morreu logo após vir ao mundo. A minha função de médico, acreditava, terminara ali.

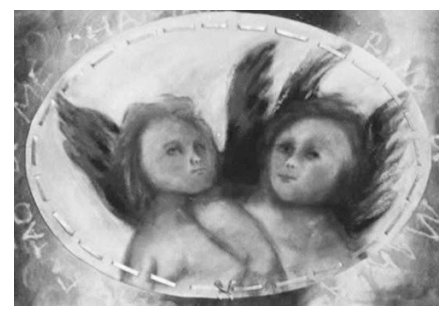


Não soube quando teve alta do hospital.

Surpreso, recebo um telefonema desta moça, seis meses depois do parto.

Pedia uma oportunidade para conversar.

Acredito que minha atitude durante sua gravidez foi o que determinou

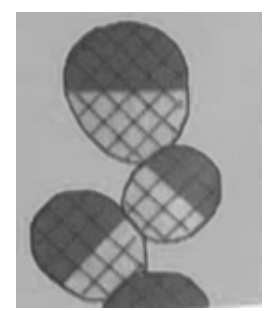
esta procura, pois ela não sabia que eu estudava Psicanálise.

Ela me conta que após alguns dias do parto começou a ter crises que poderíamos chamar de crises de pânico. Repentinamente e em qualquer lugar sentia um intenso suor frio, tremor, sensação de desfalecimento $e$ de morte iminente. Recorria ou era levada ao local onde sempre buscou auxilio, o Hospital Universitário. Lá, no Pronto Socorro, diziam após a realização de um eletrocardiograma, que ela nada tinha. Pude conhecer a humilhação sentida pela pessoa que se encontra nestas condições. Todo o ser está gritando por ajuda, o sofrimento é concreto e cruel. No entanto, nessas horas, o médico, na estrutura médica existente, com sua necessidade de rapidez e cientificismo, com freqüencia desconsidera o sofrer e o fato de que foi para ele que a demanda de cuidado se fez. Em uma dessas idas ao Pronto Socorro encaminharam-na para o Setor de Psicologia.

Feita uma entrevista com a psicóloga, ficou sabendo que três eram as sessões de psicoterapia permitidas para cada paciente (pelo menos foi o que me contou). Sentiu que mais uma vez não havia espaço de acolhimento para lidar com o mal que a atacava, sem nem mesmo saber o porquê.

Conversando com ela, ouvindo essas histórias, entendi que muitas outras questões estavam envolvidas com aquela gravidez. Era necessário poder ouvir e buscar um caminho entre suas lembranças e seus temores atuais. Só em parte o médico pode prover este ambiente, $e$ foi então que propus que nos encontrássemos no consultório de psicanálise. Ela concordou, e hoje penso ter sido um convite acertado, pois deste trabalho surgiu a condição de interromper as crises e retomar sua vida afetiva e profissional.

Em pequenas doses, foi se constituindo uma longa história, em que não faltava nenhum ingrediente. Alegrias, tristezas, desilusões, ilusões ...

$\mathrm{Na}$ particularidade da sua vida podemos, a posteriori, perceber que em todos os encontros muitos são os planos concomitantes de vivência da experiência, $e$ muitas as interpretações coexistentes de um único acontecimento.

Fiquei sabendo que a gravidez foi planejada por ela, contra a vontade de seu parceiro, que não assumiu a paternidade, mas isto não importava. Ela sonhava há muito com a oportunidade de ter um filho. Este sonho, tão comum, ou mesmo universal, tinha características muito especiais no caso desta moça. Ela acreditava que, ao engravidar, toda uma vida de sofrimentos iria desaparecer de suas lembranças, pois ela seria a família perfeita para o filho, e este para ela.

Não era apenas um sonho, era uma crença. Logo aos primeiros meses de gravidez, ela largou o emprego - do qual dependia financeiramente acreditando que ela e o bebê se bastariam para uma vida feliz. Sem imaginar que justamente por estar esperando um bebê é que precisaria, ainda mais, do emprego.

Ela era uma dentre oito irmãos, de uma família muito pobre. Cresceu sem sentir muita atenção materna. Pelo menos não tanto quanto desejava. Teve que trabalhar muito cedo. Dos seus familiares foi a única que estudou e conseguiu um bom trabalho como secretária, o que permitiu a ela morar 
sozinha em um bom apartamento.

Imagino, por sua história de sucesso profissional, e pelo grande número de amigos, que ninguém poderia imaginar a força das marcas que sua vida tinha deixado. A vitalidade do desejo de afastar o sofrimento convivia em segredo com um cotidiano aparentemente feliz. Eu, e talvez mais alguém da equipe que acompanhava sua gestação, percebemos que algo de diferente havia com aquela moça. Creio que somente nesta situação limite para a mulher, a maternidade, o sonho começou a sobrepujar a realidade. Ela, diferentemente das outras gestantes, não aparentava tristeza com a noticia que tinha recebido. Ao contrário, vinha feliz a cada retorno, sem demonstrar qualquer preocupação. Continuava vivendo seu sonho, sem se interessar pelos fatos.

Após a morte da criança entrou em profunda depressão e, como já disse, passou a ter crises de pânico. Recusava-se a abdicar de seu sonho. Ela era, em determinada medida, mais o sonho do que a pessoa que seus amigos e vizinhos conheciam. Passou a escrever todas as noites um diário no qual conversava com seu bebê.

Foi um longo processo de luto, com momentos de profundo desapego à vida. Descobrimos que os sintomas que acompanhavam as crises eram os mesmos que sentiu quando a bolsa amniótica rompeu. "Naquele momento eu sabia que já não poderia fugir", disse ela.

Trago para a superfície estes detalhes do tratamento psicanalítico para reforçar aquilo que muitos profissionais já sabem intuitivamente. Para responder à demanda que surge a cada dia, a cada encontro, a cada olhar, não basta a perícia técnica. É preciso se deixar tocar pelo desconhecido sem rejeitálo.

No campo técnico e estatístico é valorizado o fato de o médico ter "visto muitos casos". No entanto, para atender a pessoa que está ali na frente, e não outra, é preciso abdicar da memória e se aventurar a ir ao encontro e se deixar encontrar. Equilibrar estes dois aspectos fundamentais do ser médico é uma arte. Justamente viver a Medicina como estilo, estética, faz um contraponto necessário à hegemonia do ideal técnico de nossos tempos.

Cito Foucault (1995, p.270): "temos apenas uma vaga lembrança da idéia, em nossa sociedade, do princípio da obra de arte, o ponto principal ao qual devemos aplicar os valores estéticos, é o si, a própria vida, a própria existência". Não se trata de auto-absorsão em um processo de isolamento que busca uma limpeza e uma perfeição imaginárias, mas de tornar a Medicina arte, no encontro poroso e transformador que envolve a criação do médico e do paciente em um mesmo movimento, unindo-os e marcando-os de forma indelével.

\section{Conclusão}

Busquei neste trabalho colocar em contato o campo da Medicina e o da Psicanálise, tendo a cartografia como método de estudo. Procurei destacar a importância de resistir às forças que pasteurizam as relações, não permitindo que haja um prolongamento e uma singularização do contato.

"Resistir a forças" não depende de uma atitude voluntária em se alinhar com uma certa forma de ser e agir. Delicadeza e sutileza não

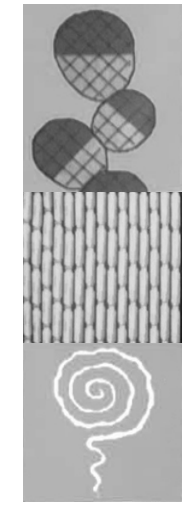


têm aqui função de modelo, mas de aspectos das relações que me ajudam a perceber o que chamei de linhas de força do contemporâneo, como a necessidade de rapidez e o cientificismo. Creio, assim, que só realizando a cartografia, a crítica, é que se cria a capacidade de, partindo da afetação que produz em cada um, mudar o alinhamento de forças.

\section{Referências}

ALVES, R. Filosofia da ciência. São Paulo: Ars Poética, 1996.

AMARAL, R. S. Uma viagem cartográfica pela instituição hospitalar, seus habitantes, suas emoções e suas implicações. São Paulo, 1999. Dissertação (Mestrado). Escola Paulista de Medicina, UNIFESP.

ARAGON, L. E. P. O valor da ecocardiografia no diagnóstico de cardiopatias fetais. São Paulo, 1996. Dissertação (Mestrado). Escola Paulista de Medicina, UNIFESP.

FOUCAULT, M. Michel Foucault entrevistado por Hubert L. Dreyfus e Paul Rabinow. In: DREYFUS, H. L., RABINOW, P. Michel Foucault: uma trajetória filosófica. Para além do estruturalismo e da hermenêutica. Rio de Janeiro: Forense Universitária, 1995. p.270.

ROLNIK, S. B. Cartografia sentimental na América: produção do desejo na era da cultura industrial. São Paulo, 1987. Tese (Doutorado). Pontifícia Universidade Católica de São Paulo.

SANT'ANNA, D. B. Corpos de passagem: ensaios sobre a subjetividade contemporânea. São Paulo:

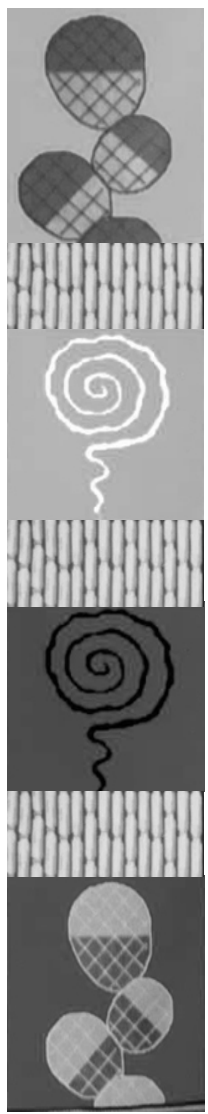
Estação Liberdade, 2001.

VIRILIO, P. Velocidade e política. São Paulo: Estação Liberdade, 1996.

ARAGON, L. E. P. La espesura del encuentro, Interface - Comunic, Saúde, Educ, v.7, n.12, p.11-22, 2003.

Este trabajo pretende realizar un análisis de la contemporaneidad efectuando una intersección entre la medicina y el psicoanálisis. Para ello se utiliza aquí el método cartográfico, con miras a evitar, tanto una perspectiva de análisis dialéctica como el aislamiento del «observador» con relación a su objeto. La escena médica y tecnológica se abre para recibir planos de comunicación-contaminación, que van más allá de la habitual relación médico-paciente para sostener la complejidad de los encuentros, que involucra factores inconscientes y virtuales. Complejidad ésta que, cuando se la considera, implica una ética particular. Se plantea el uso de aquello que se llama «casi conceptos»; en este caso, la delicadeza y la sutileza, para auxiliar en la tarea cartográfica de determinar los planos compuestos en el encuentro. Se rechaza el voluntarismo que deriva en la producción de «manuales de conducta», para buscar «líneas de fuerza» que atraviesan el espacio contemporáneo y la dupla en el inmersa, líneas éstas consideradas como preindividuales.

PALABRAS CLAVE: Medicina; Psicoanálisis; Cartografía; ultrasonografía. 